\title{
Comparison Between Clinical Features and Residual Depressive Symptoms of Patients with Bipolar Depressive and Unipolar Depressive Disorder in Remission
}

\author{
Esma Yenilmez ${ }^{1}$, Neslihan Akkişi Kumsar ${ }^{*}$, Emel Koyuncu Kütük ${ }^{3}$ and Nesrin Dilbaz ${ }^{4}$ \\ ${ }^{1}$ Niğde Public Hospital, Turkey \\ ${ }^{2}$ Sakarya University Training and Research Hospital, Turkey \\ ${ }^{3}$ Adıyaman University Training and Reserch Hospital, Turkey \\ ${ }^{4}$ Üsküdar University NP Hospital, Turkley
}

\begin{abstract}
Introduction: Even though particularly bipolar depression and unipolar depression, which are among mood disorders, seem to be similar, they show differences in terms of the course and treatment process. It is important to determine the distinctive features and predictors of these two disorders.

The purpose of this study was to examine the differences between the sociodemographic and clinical features and residual depressive symptoms in the unipolar depressive and bipolar depressive disorder groups.

Method: The study consisted of patients who applied to the Psychiatry Polyclinic of Ankara Numune Training and Research Hospital between 01.10.2010-01.05.2011 and were diagnosed with Bipolar Affective Disorder and Recurrent Major Depression according to SCID-I. As a result of the interviews, 96 patients with Bipolar Affective Disorder and 58 patients with Recurrent Major Depression, who were stable according to CGI, received a score of 7 and below from the hamilton rating scale for depression and a score of 5 or below from the young mania rating scale, were included in the study. Then sociodemographic information form, hamilton rating scale for depression, young mania rating scale, $\mathrm{CGI}$ and TEMPS-A Temperament scale were performed on patients which were deemed appropriate by applying the Structured Clinical Interview (SCID-I) for DSM-IV-TR Axis I Disorders.
\end{abstract}

Results: The comorbidity rate of psychotic features was high in a statistically significant way in the BAD group $(<0,001)$. The episodes of patients in the BAD group were higher in a statistically significant way, in terms of seasonal cycle compared to the MD group $(<0,001)$. Considering the Hamilton depression subscales individually; the scores of psychic anxiety, general somatic symptoms and suicide (consideration of life not worth living) were higher in the MD group, compared to the BAD group. In the BAD group, on the other hand, scores of the genital symptoms and retardation were higher in a statistically significant way, compared to the MD group. Scores of depressive mood, guilt thoughts, suicide (consideration of life not worth living), loss of interest in work and activities as before and somatic anxiety were higher in individuals with anxious temperament.

Conclusion: As a consequence, this study determined different residual symptoms in the bipolar affective disorder and major depression groups in remission, which shows a parallelism with the previous data. While psychic anxiety, general somatic symptoms and suicidal ideation were generally observed in unipolar depression, sexual side effects and retardation were in the forefront in the BAD group. Regarding patients who applied to the hospital with the first episode of depression, symptoms observed during the episode, case history, and residual depressive symptoms might give information to us about distinguishing the unipolar depression and bipolar disorder depressive episode.

Keywords: Bipolar depressive; Depression; Unipolar depressive patients

\section{Introduction}

Mood is a state for an individual to be in a comfortable, cheerful, sad, restless, angry, delirious or depressed affect at various levels for a while [1]. Mood disorders are shortly divided into two parts as depressive disorders and bipolar disorders according to the type of mood episodes [2].

Depression typically progresses with a depressive mood that is accompanied by collapse, anhedonia, sadness and sorrow encountered when usual activities and states do not give pleasure to the individual and attract his/her attention as before. In addition, it is possible to encounter with psychomotor retardation that is caused by lack of energy in both mental and physical areas, restriction of thought content, distinct cognitive retardation and decrease in personal functionality in depression [3].

Depression has a highly heterogeneous clinical presentation and involves various subtypes. These various presentations could be classified as melancholy, endogenous depression, atypical depression, agitated depression, psychotic depression, neurotic-reactive depression, chronic depression, double depression, minor depressive disorder, recurrent short depressive disorder, postpartum depression, premenstrual syndrome, masked depression, seasonal depression,

*Corresponding author: Neslihan Akkişi Kumsar, MD, Sakarya University Training and Research Hospital, Turkey, Tel: 90505 6451589; E-mail: drneslihankumsar@gmail.com

Received February 02, 2014; Accepted April 18, 2014; Published April 26, 2014

Citation: Yenilmez E, Kumsar NA, Kütük EK, Dilbaz N (2014) Comparison between Clinical Features and Residual Depressive Symptoms of Patients with Bipolar Depressive and Unipolar Depressive Disorder in Remission. J Psychiatry 17: 119 doi: 10.4172/1994-8220.1000119

Copyright: (c) 2014 Yenilmez E, et al. This is an open-access article distributed under the terms of the Creative Commons Attribution License, which permits unrestricted use, distribution, and reproduction in any medium, provided the original author and source are credited 
Citation: Yenilmez E, Kumsar NA, Kütük EK, Dilbaz N (2014) Comparison between Clinical Features and Residual Depressive Symptoms of Patients with Bipolar Depressive and Unipolar Depressive Disorder in Remission. J Psychiatry 17: 119 doi: 10.4172/2378-5756.1000119

Page 2 of 7

and bipolar depression [4]. Major depressive disorder has a lifelong prevalence of $15 \%$, which might even increase to $25 \%$ in women [5].

Bipolar disorder is a chronic and debilitating state that is characterized by hypomanic, manic, depressive and mixed attacks and might frequently be accompanied by behavioral, cognitive and perceptual anomalies [6-8]. Bipolar disorder might be divided into three groups as bipolar I disorder (accompanied by manic and depressive episodes), bipolar II disorder (accompanied by hypomanic and depressive episodes), and bipolar III disorder (accompanied by hypomanic episodes that are stimulated with somatic treatment) [9]. Bipolar- I disorder is encountered less frequently than the major depressive disorder and its lifelong prevalence is $1 \%(5)$.

The studies show that bipolar depressive episode is encountered earlier in the course of bipolar disorder, repeats more often and lasts longer; it is more related with intra-episode and inter-episode morbidity and mortality and causes mortality at a greater level compared to mania. The disorder primarily starts with depressive symptoms in a great majority of patients. High rates of hospitalizations indicate the acute effect of depressive phases [10].

The distinction between unipolar and bipolar diseases was established in the studies of Pierre Falret and Jules Baillarger and then Angst, Peris, and Winokur et al., who showed that there were nosological differences between bipolar and unipolar disorders in terms of clinical, genetic and course features, validated this distinction. In addition, there were many areas corresponding between two disease groups, which raised the question regarding presence of the possible clinical subtypes between the depressive and manic edges of affective diseases.

In 2007, Vieta et al. compared 58 unipolar depressive patients and 120 patients with bipolar affective disorder in remission among themselves and with 60 healthy individuals in the control group according to the hamilton rating scale for depression. As a result of this study, it was interpreted that UD patients in remission might have greater residual symptoms, which would be accompanied especially by anxiety and somatic symptoms [11].

In a study that was conducted by Pınar Çetinay Aydın et al. on patients with major depressive disorder in 2010; the most frequent residual symptoms were respectively determined as somatic anxiety, genital symptoms, depressive mental state and sleeplessness in the beginning of nights. It was determined that patients who had genital symptoms as residual symptoms had a higher risk of recurrence in follow-up, compared to those who did not [12]. Examining the studies [13-15] that investigate the effect of residual symptoms on recurrence, it is asserted that a partial improvement increases the recurrence risk of residual symptoms; however, they do not indicate which residual symptoms are effective individually.

Among mood disorders, especially bipolar depression and unipolar depression seem to be similar disorders; however they show differences in terms of course and treatment process. It is important to determine the distinctive features and predictors of these two disorders.

Hypotheses of our study are as follows; patients with major depressive disorder in remission might have greater and more different residual depressive symptoms compared to patients with bipolar depressive disorder and based on this difference, the residual depressive symptoms that are observed in follow-ups of patients who apply to hospitals with the first episode of depression might be warning for us about unipolar depression or bipolar depression. In the light of these hypotheses, the purpose of the study is to examine the differences between sociodemographic and clinical features in the Unipolar Depressive Disorder and Bipolar Depressive Disorder group and residual depressive symptoms.

\section{Material and Method}

\section{Patient selection}

The study consisted of patients who applied to the Psychiatry polyclinic of Ankara Numune Training and Research Hospital between 01.10.2010-01.05.2011 and were diagnosed with Bipolar Affective Disorder and Recurrent Major Depression according to SCID-I. As a result of the interviews, 96 patients with Bipolar Affective Disorder and 58 patients with Recurrent Major Depression, who were stable according to CGI, received a score of 7 and below from the hamilton rating scale for depression and a score of 5 or below from the young mania rating scale, were included in the study. The study was approved by the Ethics Committee of Ankara Numune Training and Research Hospital. Patients, who accepted to participate in the study, signed the informed consent form. Socio-demographic data form, hamilton rating scale for depression, young mania rating scale, and clinical global impression scale were applied on patients to be included in the study.

\section{Inclusion Criteria of the Study:}

According to the interview performed based on SCID, being diagnosed with recurrent major Depressive Disorder (Unipolar Disorder) and Bipolar depressive Disorder (the last episode should be depression for Bipolar Disorder), which meets the diagnostic criteria of DSM-IV-TR and is determined to be in remission for the last 6 months and above and according to DSM-IV-TR.

Being aged 18-65.

According to DSM-IV, having no other diagnosis with these diagnosis groups.

Having accepted to participate in the study.

Being a primary school graduate at least to be able to answer the tests.

Having no organic disorder that might prevent the clinic and answering the test.

Exclusion Criteria of the Study;

Mental retardation

Rejecting to participate in the study

History of a neurological disease or damage

Having substance abuse, which has continued for the last 6 months

Having history of a head trauma that caused a loss of consciousness for more than 5 minutes

Being out of ages of $18-65$

Having gone through a single depressive episode

\section{Procedure}

The doctor conducting the study informed patients about the study in the 2th Psychiatry Clinic of Numune Hospital, their written consent was received and their sociodemographic characteristics were recorded. the sociodemographic information form, hamilton depression rating scale, young mania rating scale and CGI were performed on patients 
Citation: Yenilmez E, Kumsar NA, Kütük EK, Dilbaz N (2014) Comparison between Clinical Features and Residual Depressive Symptoms of Patients with Bipolar Depressive and Unipolar Depressive Disorder in Remission. J Psychiatry 17: 119 doi: 10.4172/2378-5756.1000119

considered as appropriate by applying the Structured Clinical Interview (SCID-I) for DSM-IV-TR Axis I Disorders.

\section{Data Collection Tools}

Socio-demographic information form: It is a semi-structured form used to determine the sociodemographic characteristics of patients, who participate in the study, and the control group. Sociodemographic information form involves demographic information such as the age, gender, educational status, marital status, settlement, job of the patient, as well as information such as the onset age of the disease, history of physical disease, history of mental disorder and history of disease in the family.

Structured clinical interview scid-i for dsm-iv-tr axis i disorders: SCID-I is a structured clinical interview scale that was developed by First et al. in order to evaluate the DSM-IV Axis I disorders [16]. This scale provides a standard application for the diagnostic evaluation, which consequently enables the diagnosis to be more reliable and symptoms to be investigated systematically. This scale, which was adapted into Turkish and whose validity and reliability studies were conducted, was used to determine whether there was any 1 . axis disorder in patient relatives and the control group or not [17].

Hamilton rating scale for depression (HRSD): The scale that is commonly used in evaluating the depression is the Hamilton Rating Scale for Depression (HRSD) [18]. It is used to measure the degree of depression. Rather than making a diagnosis, it is used to follow the course of depression. The original scale that was prepared by Hamilton has 17 items [19]. Other forms of the HRSD are also used from time to time except for its 17 -item form, which is the most frequently used. It is in tendency to assess the somatic complaints. Each item is scored between 0 and 4 . The highest score is 53 . It validity and reliability for Turkey was conducted by Akdemir et al. [20]. In our study, we grouped those who got no score from the questions of the hamilton rating scale for depression as "no complaint" and those who got a score of one and above as "complaint exists".

Young mania rating scale: Scales aimed at measuring the severity of the manic state started to be developed in the 1970s and Young et al. developed the mania rating scale in 1978 (Young Mania Rating Scale, YMRS) [21]. In spite of many scales developed, the scale that is most commonly used in measuring the severity of the manic state in today's clinical researches is the Young Mania Rating Scale. Involving 11 items, the Young Mania Rating Scale is a rating scale where each item measures five severity rates. Validity and reliability of Young Mania Rating Scale for Turkey was conducted by Karadağ et al. [22].

Clinical global impression (CGI): It was developed by Guy et al. in order to assess the course of all psychiatric disorders in every age for clinical researches [23]. Being a three-dimension scale, CGI is filled by the doctor in an attempt to evaluate the responses of individuals with psychiatric disorders to the treatment during the semi-structured interview.

(CGI-SI): It is a scale with totally seven points. Individual with the psychiatric disorder is evaluated between 1 and 7 points according to the severity of the disorder while the scale is being filled; $1=$ Normal, not ill, $2=$ at the borderline of mental disorder, $3=$ Mildly ill, $4=$ Moderately ill, $5=$ Markedly ill, $6=$ Severely ill, $7=$ extremely ill.

(CGI-GI): It is a scale with totally seven points.

Individual with the psychiatric disorder is evaluated between 1 and 7 points according to how she/he has changed compared to her/ his state at the beginnig of the study; $1=$ very much improved, $2=$ much improved, $3=$ Minimally improved, $4=$ No change, $5=$ Minimally worse, $6=$ much worse, $7=$ very much worse.

III. Clinical Global Impression-Efficiency: It is evaluated on the basis of totally 4 points.4,3.

\section{Statistical Analysis}

The data were analyzed in the SPSS for Windows 11,5 software program. Shapiro Wilk test was used to investigate whether the continuous variables had a near-normal distribution or not. While descriptive statistics were showed as mean \pm standard deviation or median (maximum - minimum) for continuous variables, categorical variables were showed as number of the case and (\%). While the significance of the difference between groups in terms of mean was investigated with the number of independent groups, one way analysis of variance is used to investigate the significance of the difference between two Student's t tests and more than two groups. The significance of the difference between groups in terms of median values was investigated with the Mann Whitney $U$ test when the number of independent groups was two and Kruskal Wallis test was used to investigate the significance of the difference between more than two groups. When the statistics of the one way analysis of variance or Kruskal Wallis test were found significant, conditions causing the difference were determined by using the post hoc Tukey or non-parametric multiple comparison test. Categorical variables were examined through Pearson's Chi-Square or Fisher's exact Chi-Square test. Results for $\mathrm{p}<0.05$ were accepted to be statistically significant.

\section{Results}

The sample group of the study consisted of totally 154 individuals (96 with bipolar depressive disorder and 58 with major depression). Age average of the bipolar affective group was $38 \pm 9.9$. Age average was $36.6 \pm 9.4$ in the major depression group and there was no difference between the major depression and bipolar disorder groups in terms of age average ( $\mathrm{p}=0.58) .41(42.7 \%)$ of the bipolar affective disorder (BAD) group were male and 57 (57.3\%) were female. 13 (22.4\%) of the major depression group were male and $45(77.6 \%)$ were female. The number of female patients was higher in the major depressive disorder group in a statistically significant and different way $(\mathrm{p}=0.037)$. Regarding the bipolar affective disorder group, $62(64.6 \%)$ were primary school graduates, $22(22.9 \%)$ were high school graduates, $12(12.5 \%)$ were college graduates. Regarding the major depression group, 30 (51.7\%) were primary school graduates, 14 (24.1\%) were high school graduates, $14(24.1 \%)$ were college graduates. There was a significant difference between groups in favor of the major depressive disorder group, in terms of educational level $(\mathrm{p}<0.05)$ (Table 1$)$.

Considering the clinical features of the study group; first episodes of patients in the BAD group started as manic episode (45\%), depressive episode (43\%) and mix episode (10\%). The rate of episodes accompanied by psychotic features was determined as $19.0 \%$ in the MD group and $50.5 \%$ in the BAD group. The comorbidity rate of psychotic features was high in the BAD group in a statistically significant way $(<0.001)$. Considering the rates of suicide attempts, it was determined that $29(30.2 \%)$ individuals in the BAD group and $12(20.7 \%)$ in the MD group had attempted suicide before. There was no significant difference between the two groups. Considering the hospitalization rates following the suicide attempt, they were high in the BAD group in a statistically significant way (BAD n:20(69\%), MD n:2 (16.7\%), $(\mathrm{p}=0.003))$. Considering the episodes of patients in the BAD group 
Citation: Yenilmez E, Kumsar NA, Kütük EK, Dilbaz N (2014) Comparison between Clinical Features and Residual Depressive Symptoms of Patients with Bipolar Depressive and Unipolar Depressive Disorder in Remission. J Psychiatry 17: 119 doi: 10.4172/2378-5756.1000119

Page 4 of 7

\begin{tabular}{|l|c|c|c|}
\hline \multicolumn{1}{|c|}{ Variables } & Bipolar (n=96) & M.Depression (n=58) & p-value \\
\hline Age (year) & $38.1 \pm 9.9$ & $36.6 \pm 9.4$ & $>0.05$ \\
\hline Gender & & & 0.034 \\
\hline Male & $41(42.7 \%)$ & $13(22.4 \%)$ & \\
\hline Female & $55(57.3 \%)$ & $45(77.6 \%)$ & \\
\hline Educational Status & & & 0.008 \\
\hline Primary School & $43(44.8 \%)$ & $20(34.5 \%)$ & \\
\hline Secondary School & $19(19.8 \%)$ & $10(17.2 \%)$ & \\
\hline High School & $22(22.9 \%)$ & $14(24.1 \%)$ & \\
\hline University & $12(12.5 \%)$ & $14(24.1 \%)$ & \\
\hline Marital Status & & & 0,007 \\
\hline Married & $59(61.5 \%)$ & $39(67.2 \%)$ & \\
\hline Single & $21(21.9 \%)$ & $14(24.1 \%)$ & \\
\hline Divorced & $16(16.7 \%)$ & $5(8.6 \%)$ & \\
\hline
\end{tabular}

Table 1: Sociodemographic Characteristics of Cases according to Groups.

during the suicide attempt, 20 (69.0\%) were in the depressive episode, $5(17.2 \%)$ were in manic episode, $3(10.3 \%)$ were in mix episode and 1 (3.4\%) was in the euthymic episode.

Examining the drug-use rates of the study group; $99 \%$ of patients in the BAD group and $81 \%$ of patients in the MD group still used drugs. $85 \%$ of patients in the BAD group used mood stabilizers and antipsychotics (AP), 9\% only used mood stabilizers (MS) and $3 \%$ used antidepressants (AD). All patients in the MD group used antidepressants. Episodes of patients in the BAD group were higher than the MD group, in a statistically significant way in terms of the seasonal cycle $(<0.001)$.

\section{Table 2 summarizes clinical features of the study group.}

Evaluating and comparing the symptoms according to the Hamilton Rating Scale for Depression; total score of the HRSD was equal in both groups. Considering the lower items of the Hamilton depression scale individually, the scores of psychic anxiety, general somatic symptoms, and suicide (consideration of life not worth living) were higher in the MD group compared to the BAD group. On the other hand, the scores of genital symptoms and retardation were higher in a statistically significant way in the BAD group compared to the MD group (Table 3 and Figure 1). General somatic symptoms and gastrointestinal symptoms were higher in women. Weight loss was higher in men. Considering those who attempted suicide, hamilton rating scale for depression had a significant highness in terms of depressive mood, guilt thoughts and genital symptoms. Depressive mood and retardation were higher in a statistically significant way in patients who had psychotic episodes. Regarding patients using drugs, the retardation was greater only in patients using mood stabilizers. Regarding those complaining about genital symptoms, it was higher in a statistically significant way in patients using both mood stabilizers and antipsychotics. The scores of retardation, psychic anxiety, general somatic symptoms, hypochondriasis and HRSD total score were higher in a statistically significant way as the age increased. Hamilton rating scale for depression was higher in those who had a low educational level, did not work and had a story of suicide attempt.

\section{Discussion}

In this study, we thought that residual depressive symptoms might be different in patients with bipolar depressive disorder and major depression in remission and we also aimed to evaluate those features as a predictor in patients applying to hospitals with the first episode of depression, in terms of the unipolar depressive episode or depressive episode of bipolar affective disorder.

\begin{tabular}{|l|c|c|c|}
\hline Variables & $\begin{array}{c}\text { Bipolar } \\
(\mathbf{n = 9 6 )}\end{array}$ & $\begin{array}{c}\text { M. } \\
\text { Depression } \\
(\mathbf{n = 5 8 )}\end{array}$ & p value \\
\hline First episode Manic & $43(45.3 \%)$ & & \\
\hline Depressive & $41(43.2 \%)$ & & \\
\hline Mixt & $10(10.5 \%)$ & & \\
\hline Hypomanic & $1(1.1 \%)$ & & $<0.001$ \\
\hline Presence of a psychotic feature & $48(50.5 \%)$ & $11(19.0 \%)$ & $<0.05$ \\
\hline Suicide attempt & $29(30.2 \%)$ & $12(20.7 \%)$ & $>0.05$ \\
\hline $\begin{array}{l}\text { Presence of a negative event during } \\
\text { suicide attempt }\end{array}$ & $11(37.9 \%)$ & $5(41.7 \%)$ & $>0.003$ \\
\hline $\begin{array}{l}\text { Hospitalization after suicide } \\
\text { Hospitalization after suicide }\end{array}$ & $20(69.0 \%)$ & $2(16.7 \%)$ & 0.003 \\
\hline History of hospitalization & $74(77.9 \%)$ & $15(26.8 \%)$ & $<0.001$ \\
\hline Age (year) of the treatment onset & $24.9 \pm 8.6$ & $30.2 \pm 7.6$ & $<0.001$ \\
\hline Drug Use & $96(100.0 \%)$ & $47(81.0 \%)$ & $<0.001$ \\
\hline Seasonal cycle & $43(45.3 \%)$ & $6(10.5 \%)$ & $<0.001$ \\
\hline
\end{tabular}

Table 2: Clinical Features of Cases according to Groups.

\begin{tabular}{|l|c|c|c|}
\hline Variables & $\begin{array}{c}\text { Bipolar } \\
(\mathbf{n = 9 6 )}\end{array}$ & $\begin{array}{c}\text { M. Depression } \\
(\mathbf{n = 5 8 )}\end{array}$ & p-value \\
\hline Depressive mood & $15(15.6 \%)$ & $10(17.2 \%)$ & $>0.05$ \\
\hline Guilt & $19(19.8 \%)$ & $16(27.6 \%)$ & $>0.05$ \\
\hline Suicide & $6(6.3 \%)$ & $10(17.2 \%)$ & 0.014 \\
\hline Sleep-onset insomnia & $29(30.2 \%)$ & $14(24.1 \%)$ & 0.225 \\
\hline Waking up at midnight & $5(5.2 \%)$ & $2(3.4 \%)$ & 0.869 \\
\hline Waking up early in the morning & $3(3.1 \%)$ & $5(8.6 \%)$ & 0.320 \\
\hline Working and activity & $28(29.2 \%)$ & $19(32.8 \%)$ & 0.614 \\
\hline Retardation & $10(10.4 \%)$ & $1(1.7 \%)$ & $>0.05$ \\
\hline Agitation & $6(6.3 \%)$ & $1(1.7 \%)$ & 0.206 \\
\hline Psychic anxiety & $21(21.9 \%)$ & $23(39.7 \%)$ & 0.048 \\
\hline Somatic anxiety & $25(26.0 \%)$ & $24(41.4 \%)$ & 0.130 \\
\hline Gastrointestinal & $6(6.3 \%)$ & $2(3.4 \%)$ & 0.608 \\
\hline General somatic & $20(20.8 \%)$ & $21(36.2 \%)$ & $<0.001$ \\
\hline Genital symptoms & $35(36.5 \%)$ & $11(19.0 \%)$ & $<0.001$ \\
\hline Hypochondriasis & $2(2.1 \%)$ & $1(1.7 \%)$ & 0.360 \\
\hline Loss of weight & $12(12.5 \%)$ & $2(3.4 \%)$ & $>0.05$ \\
\hline Table 3 Frequ)
\end{tabular}

Table 3: Frequency Distribution of Cases regarding the Sub-Problems of HRSD according to Groups.

In our study, there was no significant difference between the major depression group and bipolar depressive disorder group in terms of age. The number of female patients was greater in the major depression group. This finding was in line with literature [24].

Considering the clinical features of patients who were included in the study; $77.9 \%$ of patients in the bipolar affective disorder group and $26.8 \%$ of patients in the major depression group were treated by hospitalization, which makes us consider the possibility for patients who were included in the study to be more resistant to treatment. This finding also explains why the bipolar affective disorder group had a greater rate of drug-use. Almost all patients in the major depression group were only treated with antidepressants. Regarding patients in the bipolar affective disorder group, 9\% were using mood stabilizers, $85.4 \%$ both mood stabilizers and antipsychotics, $3 \%$ antipsychotics and $2 \%$ only antidepressants. Considering the period without treatment, it was an average of 0.6 year ( $0-20$ years) in the bipolar affective disorder group and 2 years ( $0-13$ years) in the major depression group. This finding also showed a parallelism with previous studies [24].

Considering the total score of the Hamilton rating scale for depression, there was no statistically significant difference between the $\mathrm{BAD}$ and MD groups. However, it was determined that some residual 
Citation: Yenilmez E, Kumsar NA, Kütük EK, Dilbaz N (2014) Comparison between Clinical Features and Residual Depressive Symptoms of Patients with Bipolar Depressive and Unipolar Depressive Disorder in Remission. J Psychiatry 17: 119 doi: 10.4172/2378-5756.1000119

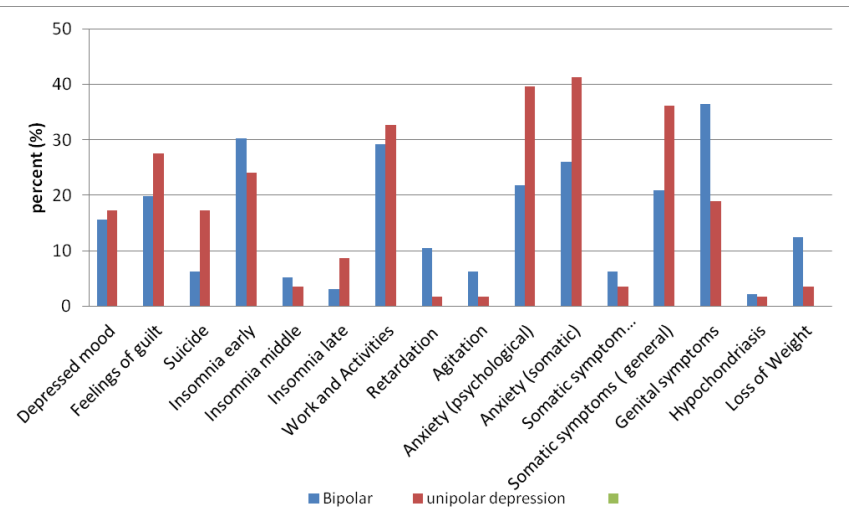

Figure 1: Symptom percentages according to the Hamilton rating scale for depression.

symptoms were ongoing. The ongoing residual symptoms might cause deterioration in both the business life and social life, retrogression between interpersonal relations and increasing rates of divorce and unemployment. These symptoms might also be regarded as the reason of nonadherence to treatment and consequently the greater rates of relapse.

While it is relatively easier to diagnose bipolar disorder in patients with an episode of mania or hypomania, the actual difficulty is to make a diagnosis for bipolar patients whose first episode starts with depression [25]. Even though there are many studies comparing the depressive symptoms of $\mathrm{BAD}$ and $\mathrm{MD}$, there is a limited number of studies on the residual depressive symptoms. In this study, we investigated the residual symptoms of patients in remission. We grouped those who got no score from the questions of the hamilton rating scale for depression as "no complaint" and those who got a score of one and above as "complaint exists" and as a result of the statistics: while the suicide thought, general somatic symptoms and psychic anxiety scores were statistically significant in the MD group; genital symptoms and retardation scores were higher in the BAD group in statistically significant way. In the study conducted by Pınar Cetinay Aydin et al. on patients in the major depression group regarding the 'effect of residual symptoms and memory functions on relapse', the most frequent residual symptoms were determined as somatic anxiety, genital symptoms, depressive mood and sleeplessness in the beginning of nights [12]. In another study that was conducted by Vita et al. in 2008 , the total score of the hamilton rating scale for depression was higher in the major depression group compared to the BAD group and the scores of anxiety and general somatic symptoms were also higher [11]. The results of our study showed a parallelism with these data. The fact that general somatic symptoms were higher in the major depression group was associated with the fact that majority of patients in this group were women and physical diseases were encountered more frequently in the major depression group. Another reason might be the fact that anxiety symptoms were also observed in these patients during the acute period. The studies show that depression that is accompanied by somatic symptoms and anxiety symptoms is more resistant to treatment and somatic symptoms recover later [13]. Ongoing residual somatic symptoms and anxiety symptoms, on the other hand, might mainly be associated with more frequent relapses and more deterioration in functionality. When patients with depression in remission, who have no history of hypomania or mania, apply to hospitals, the presence of somatic symptoms and psychic anxiety might make us think about the unipolar depression if we do not question the disease symptoms and family history. Considering the fact that the presence of residual symptoms is associated with frequent relapses and resistance to treatment, it might be warning for us about changing or augmenting the treatment.

On the other hand, the score of genital symptoms was higher in the BAD group, which might be due to drugs. Considering the druguse of patients with genital symptoms, majority of them were treated with DDD + AP. Considering the sexual side effects of these drugs, it is possible that these symptoms are the side effects of drugs rather than residual symptoms. The fact that our study has also found the genital symptoms high in the remission period emphasizes the importance of selecting drugs with a minimum genital side effect in particular.

In our study, retardation was another symptom that was found to have a higher score in the BAD group. This complaint is also thought to be a side effect caused by drugs. Examining the drugs used by those patients with that complaint, we mainly found DDD. While a greater rate of retardation was expected in those receiving $\mathrm{DDD}+\mathrm{AP}$, the retardation was greater in those using DDD, which makes us think that this complaint might not be the side effect of a drug. This finding could also be interpreted as an indicator of a greater deterioration in cognitive competences in the BAD group. In studies examining depressive symptoms in the acute period, the retardation is indicated to be mainly encountered in the bipolar depressive disorder [26]. The clinic of bipolar depressive episode resembles the clinic of atypical depressive episode [27]. Being asserted to be more effective in the treatment of atypical depression treatment, MAOI may give more successful results in the bipolar affective disorder group when it is performed by taking manic and hypomanic shifts into account.

Considering the distribution of general symptoms; depressive mood, guilt thoughts and genital symptoms were greater in those attempting suicide. It might be thought that depressive mood and guilt thoughts might induce the suicide. Abundance of genital symptoms might be associated with the more aggressive treatments given by patients due to the previous suicide attempts of these patients. The last episodes of patients with genital symptoms generally occur as manic episode, which makes us think that manic episode might have greater genital symptoms since more antipsychotics are used. Comparing in terms of age averages; as the age increases, an increase was also observed in the total score of hamilton rating scale for depression, retardation, psychic anxiety, general somatic symptoms, hypochondriasis and genital symptoms. This finding seems to be warning regarding the evaluation of elder individuals with somatic complaints also in terms of depression. Total score of Hamilton scale was found higher in those who had no suicide attempt before, did not work and had advanced age. Since somatic symptoms increase as the age increases, the increase in the total score might be related with this finding.

The diagnosis of bipolar disorder might generally be skipped and patients are unable to receive a true diagnosis and treatment for long years [27]. The most important reasons of this condition include the negligence of the doctor to ask especially about hypomanic periods and consequently failure of the patient to specify it, consideration of this condition a way of recovering from depression rather than a disease and liking it. Thus, it is very important to systematically question the previous manic and hypomanic periods in each patient with depression in terms of a true diagnosis. Besides, it is also required to receive a detailed history from families due to the insight deficiency or cognitive disorders regarding the hypomanic periods of these patients [28]. Since it is difficult to enable the patients to be followed by only one doctor 
Citation: Yenilmez E, Kumsar NA, Kütük EK, Dilbaz N (2014) Comparison between Clinical Features and Residual Depressive Symptoms of Patients with Bipolar Depressive and Unipolar Depressive Disorder in Remission. J Psychiatry 17: 119 doi: 10.4172/2378-5756.1000119

Page 6 of 7

regularly under the conditions of our country, we are not able to see the patients during episodes all the time. We could follow majority of them during the partial remission or remission or just write out a prescription. Considering the frequent rates of depression and losses, it is required to know both the episode period and symptoms in followups very well and conduct the treatment accordingly.

Today's DSM system grounds the distinction of bipolar and unipolar only on the presence of manic or hypomanic episode. Being related with the advancing course of the disease, this distinction prevents the cases with bipolar disorder who have not had a manic/hypomanic episode yet to be recognized. Thus, it is very important to reveal the clinical, demographic and biological differences between unipolar and bipolar depression. A distinction based on these features will direct the clinician regarding the course of disease and treatment options.

Even though the purpose of this study was to make the distinctive diagnosis of unipolar and bipolar depression as many studies showed that residual symptoms were related with high competence destruction we also need to determine our treatment goal at this point. The clinician should aim to sustain the treatment until the patient fully recovers, not until she/he is in remission [29]. Although the recovery has a disputable definition, recovery is accepted as the sustainment of remission for at least 6 months by many authors [30]. In their study, Judd et al. (2002) indicated that loss of competence continued in those with residual depression compared to those who did not have any depressive symptom, and they had lifelong suicide thoughts and attempts [31]. Considering the fact that residual depressive symptoms cause loss of function in many areas of life and are associated with frequent relapses, it is required to carefully evaluate the symptom severity of patients with depression and continue the antidepressant treatment in a sufficient duration and dosage. In order to do this, we should make a distinction between these two groups. Unless we do, manic and hypomanic shifts will be observed in patients in the bipolar affective group.

The primary limitation of our study was that the major depression group had fewer number. This was associated with the fact that pure depression was encountered less and we received a limited number of patients since patients in the polyclinic were mainly comorbid with the anxiety findings. The second limitation was that Hamilton Rating Scale for Depression did not consider symptoms known as reverse neurovegetative symptoms such as increased sleep, appetite and weight. Thus, total scores of HAM -D might be lower. Patients with atypical depressive symptoms might obtain lower scores from HAM-D. Other authors also emphasized that the HAM-D scale with 17 items was insufficient in terms of involving the reverse neurovegetative symptoms in the measurement [32].

As a consequence, our study determined different residual symptoms in the bipolar affective disorder and major depression group in remission, which shows a parallelism with the previous data. While psychic anxiety, general somatic symptoms and suicidal ideations were mainly observed in the unipolar depression group; sexual side effects and retardation were in the foreground in the BAD group. In patients who apply to hospitals with the first episode of depression, as well as symptoms during the episode and history, the residual depressive symptoms may give us information about the distinction of unipolar depression and bipolar disorder depressive episode. Future studies are required to give information about the effect of residual depressive symptoms on relapse and whether it will give information about the type of the next episode in the bipolar disorder group or not.

\section{References}

1. Öztürk MO (2001) Mental Health and Disorders. Ankara: Nobel Tıp Kitapevler Ltd. Sti 292-428.

2. Güleç C, Köroğlu E (1998) Essential Textbook of Psychiatry. Volume 1, Ankara Publication Association of Physicians 391-430.

3. Işık, E (2003)Mood Disorders, Depression and Bipolar Disorders. t: ışık E editor. Bipolar Disorders. Istanbul: Printing House of Visual Arts467-509.

4. Aşkın R (1999) Depression Manual 2nd Edition Roche Müstahzarları Sanayi A.S, Konya.

5. Kaplan HI, Sadock BJ (2004) Concıse Textbook of Clinical Psychiatry Translation: Abay E. Kaplan \& Sadock Klinik Psikiyatri. İstanbul: Nobel Tip Kitapevleri159-177

6. Weissman MM, Bland RC, Canino GJ et al (1996) Cross-national epidemiology of major depression and bipolar disorder. JAMA276: 293-299.

7. Keck PE, McElroy SL, Arnold LM (2001) Bipolar disorder. Med Clin North Am 85: 645-661.

8. Kessler RC, McGonagle KA, Zhao S (1994) Lifetime and 12-month prevalence of DSM III-R psychiatric disorders in the United State: Results from the National Comorbidity Survey. Arch Gen Psychiatry 51: 8-19.

9. Ceylan ME, Oral ET (2001) Biological Psychiatry in Research and Clinical Practice volume: 4 Mood Disorders. Istanbul: Copyright by M. Emin Ceylan 28-69.

10. Bowden CL (2001) Strategies to reduce misdiagnosis of bipolar depression. Psychiatr Serv52: 51-55

11. Vieta E, Sánchez-Moreno J, Lahuerta J, Zaragozav S (2008)For the EDHIPO Group (Hypomania Detection Study Group) Subsyndromal depressive symptoms in patients with bipolar and unipolar disorder during clinical remission. J Affect Disord 107: 169-174

12. Aydın CP, Gülseren Ş, Mandacı H (2010) The Effects of Residual Symptoms and Memory Functions on Relapse in Patients with major Depressive Disorder: A Controlled Follow-up Study, Archives of Neuropsychiatry 47: 4-8

13. Pintor L, Gasto C, Navarro V (2003) Relapse of major depression after complete and partial remission during a 2-year follow up. J Affect Disord73:237-244

14. Paykel ES, Ramana R, Cooper Z (1995) Residual symptoms after partia remission: an important outcome in depression. Psychol Med25:1171-1180.

15. Van Londen L, Molenaar RP, Goekoop JG (1998) Three-to 5-year prospective follow up outcome in major depression. Psychol Med 28:731-735.

16. First MB, Gibbon M, Spitzer RL, Williams JBW (1997) Structured Clinica Interview for DSM-IV(SCID). Washington: American Psychiatric Assosiation.

17. Çorapçıoğlu A, Aydemir Ö, Yıldız M, Esen E, Köroğlu E (2009) Structured Clinical Interview for Axis II Disorders for DSM-IV Clinical Version. Ankara: Published by Physicians Broadcasting Union. (Turkish)

18. Aydemir Ö, Köroğlu E (2009) Clinical scales used in Psychiatry. Ankara: HYB Basım Yayın 479-480.(Turkish).

19. Hamilton M (1959) The assessment of anxiety states by rating. $\mathrm{Br} \mathrm{J}$ Med Psychol 32: 50-55.

20. Akdemir A, Örsel S, Dağ I, Türkçapar H, İçcan N, Özbay H (1996) Validity, reliability, and clinical use of Hamilton rating scale for depression. Psychiatry, Psychology Psychopharmacology Journal 4: 251-9.

21. Young RC, Biggs JT, Ziegler VE, Meyer DA (1978) A rating scale for mania reliability, validity and sensitivity. Br J Psychiatry133: 429-435.

22. Karadağ F, Oral T, Aran Yalçın F, Erten E (2001) Validity and reliability of Young Mani Rating Scale in Turkey. Turkish Psychiatry Journal 13: 107-114.

23. Guy W (1976) Clinical Global Impressions: In ECDE Assessment Manual for Psychopharmacology218- 222. Revised DHEW Pub. (ADM). Rockville, MD: National Institute for Mental Health.

24. Sadock B, Sadock V (2005) Kaplan\&Sadock's Comprehensive Textbook of Psychiatry, eighth edition, volume 1, Mood disorders, Lippincott Williams\&Wilkins, Philadelphia USA

25. Maj M, Akiskal H, Lopez-lbor J, Sartorius N (2002) Bipolar Disorder, John 
Citation: Yenilmez E, Kumsar NA, Kütük EK, Dilbaz N (2014) Comparison between Clinical Features and Residual Depressive Symptoms of Patients with Bipolar Depressive and Unipolar Depressive Disorder in Remission. J Psychiatry 17: 119 doi: 10.4172/2378-5756.1000119

Wiley\&Sons Ltd, Bipolar Disorder (Translation Editor: T. Oral) Medikal Yayın, İstanbul 2002

26. Perugi G, Akiskal HS, Lattanzi L, Cecconi D, Mastrocinque C, et al.(1998) The high prevalence of "soft" bipolar (II) features in atypical depression. Compr Psychiatry 39: 63-71

27. Parker G, Roy K, Wilhelm K (2000) The nature of bipolar depression: implications for the definition of melancholia. J Affect Disord 59: 217-224

28. Ghaemi SN, Sacks GS, Chiou AM (1999) Is bipolar disorder still underdiagnosed? Are antidepressants overutilized? J Affect Disord 52: 135-144
29. Bakish D (2001) New standard of depression treatment: remission and full recovery. J Clin Psychiatry, 62: 5-9.

30. Frank E, Prien RF, Jarrett RB, Keller MB, Kupfer DJ et al. (1991) Arch Gen Psychiatry, 48: 851-855.

31. Judd LL, Akiskal HS, Schetter PJ, et al. (2002) The long-term natural history of the weekly symptomatic status of bipolar I disorder. Arch Gen Psychiatry59: 530- 537.

32. Nierenberg AA, DeCecco LM (2001) Definitions of antidepressant treatment response, remission, nonresponse, partial response and other relevant outcomes: a focus on treatment-resistant depression. J Clin Psychiatry 62: 5-9. 